\title{
Addressing Cardiovascular Disease in Women: Focus on Dyslipidemia
}

\section{Emma A. Meagher, MD}

Background: There is a need to better diagnose and treat women who may be at risk for cardiovascular disease. This is emphasized by the impending release of evidence-based guidelines for the prevention of cardiovascular disease in women. Dyslipidemia is one of the most important modifiable risk factors for coronary heart disease (CHD) and is the focus of the current literature review.

Methods: Medical literature on treating cardiovascular disease and cholesterol disorders in women was reviewed by searching Medline, including a selective search for randomized controlled clinical trials of lipid therapy. In addition, current dyslipidemia treatment guidelines were reviewed.

Results and Conclusions: Subgroup analyses of both primary and secondary prevention trials have shown that lipid-modifying drugs offer benefits to women comparable with those seen in men. Lowdensity lipoprotein cholesterol (LDL-C) is the primary target of lipid-modifying therapy for the reduction of coronary risk. However, there are differences between the sexes in the lipid profile that may have clinical implications. In women, changes in high-density lipoprotein cholesterol (HDL-C) and triglyceride levels are better predictors of coronary risk than LDL-C or total cholesterol. Thus, treatment beyond LDL-C may be of greater importance in women than in men. Furthermore, treatment options that provide improvement in all aspects of the lipid profile should be considered. ( $\mathrm{J}$ Am Board Fam Pract 2004;17:424-37.)

Cardiovascular disease is the primary cause of death in American women, accounting for more than 500,000 deaths per year. ${ }^{1}$ More women die from cardiovascular disease each year-1 of every 2 -than from the next 7 leading causes of death combined. ${ }^{1}$ Despite these statistics, surveys show that neither women nor their physicians appreciate the magnitude of this risk. In a survey of 1000 women aged 25 years and older, only $8 \%$ cited cardiovascular disease as their greatest health concern, and less than $30 \%$ reported that their physician had discussed cardiovascular risk with them. Furthermore, of women who were informed about cardiovascular disease, only $18 \%$ identified their health care provider as the source of that knowledge. ${ }^{2}$

Although death rates from coronary heart disease (CHD) in men have been decreasing over the past 2

Submitted, revised, 12 July 2004.

From the University of Pennsylvania, Philadelphia. Address correspondence to Emma A. Meagher, MD, Department of Medicine and Pharmacology, University of Pennsylvania School of Medicine, 9053 West Gates, 3400 Spruce St., Philadelphia, PA 19104-4283 (e-mail: emma@spirit.gcrc. upenn.edu).

This work was supported in part by an unrestricted educational grant from Kos Pharmaceuticals, Inc. decades, most notably since the introduction of statin therapy, rates have continued to rise in women. This increase may in part be a result of the coincident widespread use of hormone replacement therapy (HRT) as a cardioprotective strategy (Figure 1). ${ }^{1}$ Recent evidence from trials such as the Women's Health Initiative ${ }^{3}$ and the Heart and Estrogen/progestin Replacement Study, ${ }^{4}$ however, have demonstrated that HRT provides no cardiovascular benefits and may actually be harmful. These studies have prompted a call to action to re-examine the issue of cardiovascular risk in women and determine appropriate strategies for risk reduction.

This review focuses on factors contributing to the under-recognition of cardiovascular risk and disease in women. It discusses associated risk factors, with a focus on dyslipidemia and reviews the therapeutic options available for effective lipid management.

\section{Factors Affecting Cardiovascular Care in Women}

The high rate of undiagnosed and/or untreated cardiovascular risk in women is in part attributed to physicians' relatively low index of suspicion for cardiovascular disease in women. In one survey, 


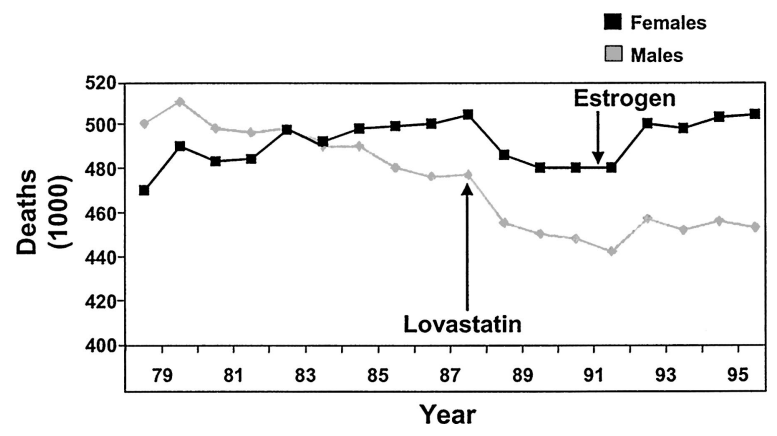

Figure 1. Cardiovascular mortality trends for males and females: United States 1979 to 1996. Arrows represent the introduction of lovastatin in 1987 and the recommendation of HRT as a preventive strategy for women in the early 1990s. [Adapted from American Heart Association. Heart disease and stroke statistics2003 update [monograph on the Internet]. Dallas (TX): American Heart Association; 2003 [cited 2003 Dec 8]. Available from: http://www.americanheart.org/ downloadable/heart/1040391091015HDS_Stats_03. pdf. Copyright (C) 2003 American Heart Association. Used with permission.]

$70 \%$ of female patients stated that their physicians had never discussed cardiovascular disease with them. ${ }^{2}$ However, women are more likely than men to have multiple risk factors for CHD. ${ }^{5}$ Both health professionals and patients need to recognize the existence of risk factors and the potential for developing future cardiovascular risk. In addition, they need to remain alert to any signs and symptoms suggestive of overt cardiovascular disease. Ongoing cardiovascular risk assessment should be a part of each female patient's medical care.

The clinical presentation of cardiovascular disease in women may be atypical and can be subtle, leading to a lack of recognition by physicians. ${ }^{6}$ Although chest pain has been reported in some studies as the most common symptom of myocardial infarction in both men and women, ${ }^{7,8}$ some reports suggest it is not as predictive in women compared with men and tends to subside more quickly. ${ }^{7,9}$ Women are more likely to experience atypical symptoms, such as shortness of breath, nausea, loss of appetite, and back pain. ${ }^{9-11}$ Diagnosing cardiovascular disease according to the symptoms common in men can cause evidence of cardiovascular disease in women to be overlooked.

Finally, even when women are identified as having risk factors for cardiovascular disease, there is lower utilization by physicians of standard accepted therapy compared with men. ${ }^{12-14}$ In comparisons of women and men with similar cardiovascular risk profiles, women have been found to be significantly less likely than men to undergo additional coronary evaluation $(38 \%$ vs $62 \% ; P=.002)$ or coronary revascularization $(2 \%$ vs $5 \% ; P=.03) .{ }^{13}$ Less aggressive lipid-modifying strategies are used when treating women compared with men with similar risk profiles. In the Heart and Estrogen/progestin Replacement Study, approximately half of the women with established cardiovascular disease were not receiving lipid-modifying medications. ${ }^{14}$ In a 3-year study of 825 men and women with CHD, use of lipid-modifying therapy increased and low-density lipoprotein cholesterol (LDL-C) decreased in men but utilization of therapy and, not surprisingly, LDL-C levels remained the same in women despite LDL-C levels above goal in the women under study. ${ }^{12}$

This may partially derive from the lack of relevant data. Dyslipidemia is one of the most important modifiable risk factors for CHD. ${ }^{15}$ However, women have been largely excluded from primary and secondary prevention trials; most available data on lipid modification in women comes from subanalyses of the relatively small female populations enrolled in clinical trials. ${ }^{5,16-19}$

An additional explanation for this discrepancy in treatment rates may be the widely held belief that cardiovascular risk is more time-dependent in women, increasing markedly only after menopause. ${ }^{20}$ The results of various large-scale observational studies documenting an increase in cardiovascular disease after menopause and a decline in risk with the use of estrogen laid the foundation for starting cardiovascular risk assessment after menopause and initiating HRT as a preventive strategy. ${ }^{1,21,22}$ Given our present understanding of the progressive nature of atherosclerosis, ${ }^{23}$ it now seems that the time demarcation at menopause may be an artificial distinction and that the presence of other factors in women may warrant the initiation of risk intervention strategies much earlier.

The issue of the effects of HRT on cardiovascular risk has been controversial. In the 1990s, HRT was found to have beneficial effects on the lipid profile $^{24}$ and was subsequently widely adopted as a cardiovascular risk-reduction strategy in postmenopausal women. Population studies also demonstrated a correlation between HRT in postmenopausal women and a decrease in cardiovascular 
risk. $^{21,22}$ Recently, however, large-scale prospective trials have provided definitive evidence that HRT does not decrease risk of cardiovascular events and, in fact, can increase the rate of thromboembolic events. ${ }^{3,4}$ In the Heart and Estrogen/Progestin Replacement Study, HRT reduced LDL-C by $11 \%$ and increased high-density lipoprotein cholesterol (HDL-C) by $10 \%$ but failed to significantly affect any of the primary or secondary cardiovascular outcome measures. ${ }^{4}$

More results contradicting the cardioprotective theory of HRT came from the Women's Health Initiative, a large-scale $(\mathrm{N}=16,608)$ primary prevention study, in which patients treated with combined estrogen and progesterone had a significant $29 \%$ higher rate of CHD than did untreated women, primarily because of a higher rate of nonfatal myocardial infarction; in addition, the risk of venous thromboembolic disease was doubled. ${ }^{3}$ The estrogen arm of WHI, which recently included 10,739 women with prior hysterectomy, was also terminated, primarily because of a lack of CVD benefit and an increased risk of stroke among those treated with estrogen. ${ }^{25}$ The Women's Angiographic Vitamin and Estrogen trial showed that HRT was associated with worse progression of CHD on angiography as well as a higher rate of cardiovascular events. ${ }^{26}$ The results of these studies have overturned the practice of using HRT as a risk-lowering strategy for cardiovascular disease or as standard therapy for dyslipidemia in women.

\section{Cardiovascular Risk Assessment}

Current guidelines recommend a comprehensive assessment of cardiovascular risk in both men and women. ${ }^{15,27,28}$ The evaluation should include a complete medical history to identify the presence of a known history of cardiovascular disease, hyperlipidemia, hypertension, diabetes, thyroid disease, and obesity. A family history for each of these should also be determined, as should a family history of premature cardiovascular disease. A laboratory work up should initially include a complete lipid panel and fasting glucose level. In patients who have known hyperlipidemia, a thyroid-stimulating hormone level should be obtained to rule out secondary hypercholesterolemia. Using both historical data and results of the physical examination and laboratory work up, patients should be evaluated for the presence of the metabolic syndrome.
The utility of obtaining serum levels for homocysteine, lipoprotein(a), or high-sensitivity C-reactive protein as part of routine cardiovascular risk assessment is hotly debated.

\section{Dyslipidemia in Women \\ LDL-C}

The association between cardiovascular events and LDL-C is well established, and abundant evidence shows a reduction in clinical events in both men and women when LDL-C levels are lowered. ${ }^{5,16-19,29-31}$ The current guidelines from the National Cholesterol Education Program (NCEP) Adult Treatment Panel (ATP) III, as well as the more recent American Heart Association (AHA) guidelines for cardiovascular disease prevention in women, reinforce LDL-C as the primary target of therapy. ${ }^{15,28}$ LDL-C levels are generally lower in women than in men until menopause, when levels increase and LDL particles become smaller, denser, and therefore more atherogenic. ${ }^{32-34}$

\section{HDL-C and Triglycerides}

The Framingham Heart Study established both HDL-C and triglycerides as important predictors for coronary events. ${ }^{35}$ This association was noted to be independent of total cholesterol level and applied to both sexes. This study was the first to suggest that triglyceride and HDL levels may have greater predictive potential in women compared with men (Figure 2). ${ }^{36,37}$ More recently, the Lipid Research Clinics' Follow-Up Study also demonstrated that both HDL-C and triglycerides were

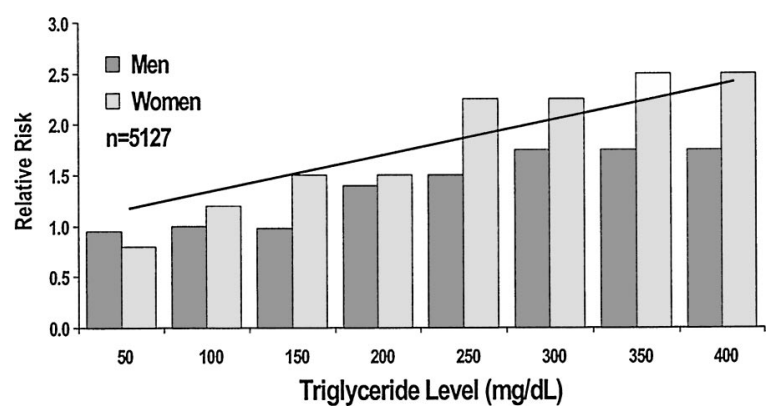

Figure 2. Risk of coronary heart disease by triglyceride level in men and women-The Framingham Heart Study. [Adapted from Castelli WP. Epidemiology of triglycerides: a view from Framingham. Am J Cardiol 1992;70:3H-9H. Copyright (ㄷ 1992 Excerpta Medica. Used with permission.] 
better predictors of coronary risk and cardiovascular mortality in women than total cholesterol or LDL-C. ${ }^{38}$ In 1995, a meta-analysis performed by Hokanson et $\mathrm{al}^{39}$ supported these data by showing that an increase in triglycerides of $1 \mathrm{mmol} / \mathrm{L}$ was associated with a $76 \%$ increased risk of cardiovascular disease in women versus $32 \%$ in men. In both ATP III and the new AHA guidelines for women, non-HDL-C is a secondary target of therapy. ${ }^{15,28}$

On average, women have HDL-C levels approximately $10 \mathrm{mg} / \mathrm{dL}$ greater than those of men, which may help account for the disparity in cardiovascular events between men and women. ${ }^{15,35}$ ATP III recognizes this sex disparity in the guidelines for diagnosing metabolic syndrome; whereas HDL-C $<40 \mathrm{mg} / \mathrm{dL}$ is a risk factor in men, HDL-C $<50$ $\mathrm{mg} / \mathrm{dL}$ is considered a risk factor in women. ${ }^{15} \mathrm{Al}-$ though the ATP III guidelines do not give different HDL-C targets for treatment based on sex, the new AHA guidelines for women recommend raising HDL-C levels $\geq 50 \mathrm{mg} / \mathrm{dL}^{28}$

\section{Lipoprotein(a)}

Lipoprotein(a) is now emerging as a risk factor for CHD. ${ }^{15}$ Data from the Heart and Estrogen/progestin Replacement Study indicate that lipoprotein(a) is an independent predictor of the risk of recurrent CHD in postmenopausal women. ${ }^{40}$ This may have important implications for therapy, because lipoprotein(a) is unaffected by diet, exercise, and most lipid-modifying medications, except for niacin and HRT, which decrease it. In ATP III, lipoprotein(a) measurement can be considered in patients with less obvious risk but who may warrant more aggressive evaluation based on the presence of a single severe risk factor. ${ }^{15}$

\section{Diabetes and Metabolic Syndrome}

According to data from the Framingham Heart Study, the relative impact of diabetes on cardiovascular mortality seems to be greater in women than in men. ${ }^{41}$ Diabetes is more common in women and is considered to essentially negate any protective effect of female sex against cardiovascular disease. ${ }^{32}$ The Nurses Health Study found that women with diabetes had a 3- to 7-fold greater risk of cardiovascular events than did age-matched control subjects. $^{32,42}$

The metabolic syndrome has also been identified as a predictor of cardiovascular risk and has been associated with the development of diabe- tes. ${ }^{15,43}$ This syndrome is characterized by a constellation of metabolic risk factors, including abdominal obesity, atherogenic dyslipidemia (low HDL-C, elevated triglycerides, and an excess of small, dense LDL particles), hypertension, insulin resistance or impaired glucose tolerance, and a prothrombotic, proinflammatory metabolic state. ${ }^{15}$ The diagnosis of metabolic syndrome can be made if 3 or more risk factors are present (Table 1). ${ }^{15}$

ATP III emphasizes the cardiovascular risk associated with this condition and suggests specifically targeting its components once LDL-C and non-HDL-C (total cholesterol minus HDL cholesterol) targets have been met. ${ }^{15}$ Lipoprotein abnormalities associated with this syndrome may not be severe and may go unnoticed; it is important, therefore, that physicians assess the overall lipid profile in both men and women. Interventions should focus on increased physical activity, weight reduction, and addressing specific risk factors, such as hypertension, prothrombotic state, and dyslipidemia.

\section{C-Reactive Protein}

The role of inflammation in the development and progression of atherosclerosis has received increased attention in recent years. ${ }^{44} \mathrm{CRP}$, a marker of systemic inflammation, has been identified as an independent risk factor for cardiovascular events, adding predictive value to that of individual lipoprotein fractions. Data from the Women's Health Study indicate that HS-CRP is related to several cardiovascular risk factors in women, including age, body mass index, blood pressure, cigarette smoking, and, to a lesser extent, HDL-C. ${ }^{44}$ In one prospective follow-up of 28,263 women over 3 years, CRP was found to be the strongest predic-

\section{Table 1. Risk Factors for Diagnosing Metabolic Syndrome ${ }^{15}$}

\begin{tabular}{ll}
\hline $\begin{array}{l}\text { Abdominal obesity } \\
\text { (waist circumference) }\end{array}$ & \\
Men & $>102 \mathrm{~cm}(>40$ inches) \\
Women & $>88 \mathrm{~cm}(>35$ inches) \\
Triglycerides & $\geq 150 \mathrm{mg} / \mathrm{dL}$ \\
HDL-C & $<40 \mathrm{mg} / \mathrm{dL}$ \\
Men & $<50 \mathrm{mg} / \mathrm{dL}$ \\
Women & $\geq 130 / \geq 85 \mathrm{~mm} \mathrm{Hg}$ \\
Blood pressure & $\geq 110 \mathrm{mg} / \mathrm{dL}$ \\
Fasting glucose &
\end{tabular}

HDL-C, high-density lipoprotein cholesterol. 
tor of cardiovascular disease, superior to several other markers of inflammation and to homocysteine and lipoprotein levels. ${ }^{45}$ However, this marker also correlates with other risk factors and may lose predictive value when adjustment for other factors occurs. ${ }^{46}$ A recent AHA scientific review suggests that monitoring patients for CRP may help clinicians identify less obvious patients who are candidates for primary preventive strategies or patients who may warrant more aggressive therapy based on test results. ${ }^{47}$

\section{Treatment Options for Dyslipidemia}

The same treatment options for dyslipidemia exist for both sexes. Current data demonstrates, as mentioned previously, that these treatment options are currently underused in women at significant risk for future coronary events. In this era after the Women's Health Initiative and the Heart and Estrogen/progestin Replacement Study, the number of untreated or suboptimally treated women has the potential to increase. Therefore, it is important to specifically monitor lipid profiles in the many women who have already discontinued or who will discontinue HRT in the near future, because their LDL-C will probably rise and their HDL-C may drop. Furthermore, although LDL-C remains the primary target of therapy, attention must also be given to elevated triglyceride levels, hence the non-HDL-C goal in addition to low HDL-C levels.

\section{Lifestyle and Behavioral Changes}

The first step to reducing overall CHD risk involves therapeutic lifestyle changes. To this end, clinicians need to encourage patients to adopt a healthy lifestyle, including smoking cessation, low fat, and possibly reduced carbohydrate diet, weight control, and regular physical activity. Specific therapeutic lifestyle recommendations are presented in detail in ATP III. ${ }^{15}$ As a general recommendation, patients should reduce their dietary intake of saturated fats $(<7 \%$ of total calories) and cholesterol $(<200 \mathrm{mg} /$ day $)$, increase their intake of foods that lower LDL-C (plant stanols/sterols and soluble fiber), reduce weight, and incorporate regular physical activity into their daily routine (30 minutes or more on most days of the week). ${ }^{15}$ Patients with the metabolic syndrome should also consider reducing their carbohydrate intake.

\section{Pharmacotherapy}

Statins (Hydroxymethylglutaryl-Coenzyme A

Reductase Inhibitors)

Statins are competitive HMG-CoA reductase inhibitors; by interfering with the rate-limiting step in cholesterol synthesis, they decrease cholesterol production and cause an up-regulation in the number and activity of LDL receptors. These changes stimulate the removal of circulating LDL-C leading to lower levels. Intermediate-density lipoproteins and very low-density lipoprotein remnants are also removed, leading to lower levels of triglyceride-rich lipoproteins. Statins are extremely effective in lowering LDL-C and should be considered first-line therapy in the majority of patients to achieve LDL-C goals. ${ }^{15,28}$ Furthermore, in women at high-risk (with $\mathrm{CHD}$ or equivalent), statins are recommended even when LDL-C is $<100 \mathrm{mg} / \mathrm{dL}$, unless contraindicated. ${ }^{28}$ Some statins also have moderate HDL-C-raising and triglyceride-lowering effects.

Before the Heart Protection Study, ${ }^{19}$ women had been underrepresented in statin trials compared with men, although most included a subset of women. Despite this fact, beneficial effects in women equal to those seen in men were demonstrated in both primary and secondary prevention trials; reductions in the relative risk for cardiovascular events have ranged from $11 \%$ to $46 \%$ (Figure 3). ${ }^{5,16-19}$ The lack of statistical significance among women seen in some of these trials compared with men is probably caused by the small numbers of female participants. A meta-analysis of 5 primary and secondary prevention randomized, controlled clinical trials, including nearly 4000 women, found an overall relative risk reduction in major coronary events of $29 \%$ in women and $31 \%$ in men with statin therapy. ${ }^{48}$ In the Cholesterol And Recurrent Events trial, there was a greater percentage reduction in coronary events in women $(n=576)$ treated with pravastatin than in men $(\mathrm{n}=3583)(46 \%$ versus $20 \%){ }^{5}$ More recently, the Heart Protection Study, which evaluated 5082 women, the largest female population so far, found that overall reductions in major vascular events with statin therapy were similar in both men and women $(25 \%$ and $20 \%$, respectively) and were unaffected by age (Figure 3)..$^{5,16-19}$

Two recent trials, the PROspective Study of Pravastatin in Elderly at Risk ${ }^{49}$ and the AngloScandinavian Cardiac Outcomes Trial-Lipid Lower- 


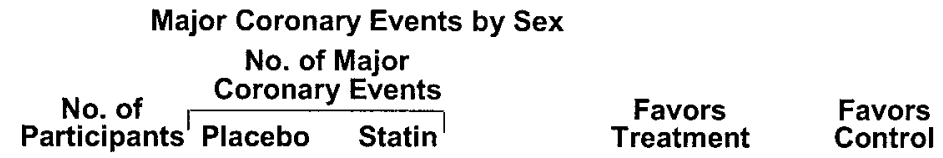

$\begin{array}{lcc}\text { Women } & & \\ \text { 4S } & 827 & 91 \\ \text { CARE } & 576 & 39 \\ \text { AFCAPS/TexCaps } & 997 & 13 \\ \text { LIPID } & 1516 & 104 \\ \text { Overall } & 3916 & \mathbf{2 4 7} \\ \text { HPS } & 5082 & 450 \\ \text { Men } & & \\ \text { 4S } & 3617 & 531 \\ \text { WOSCOPS } & 6595 & 248 \\ \text { CARE } & 3583 & 235 \\ \text { AFCAPS/TexCaps } & 5608 & 170 \\ \text { LIPID } & 7498 & 611 \\ \text { Overall } & \mathbf{2 6 9 0 1} & \mathbf{1 7 9 5} \\ \text { HPS } & 15454 & 2135\end{array}$

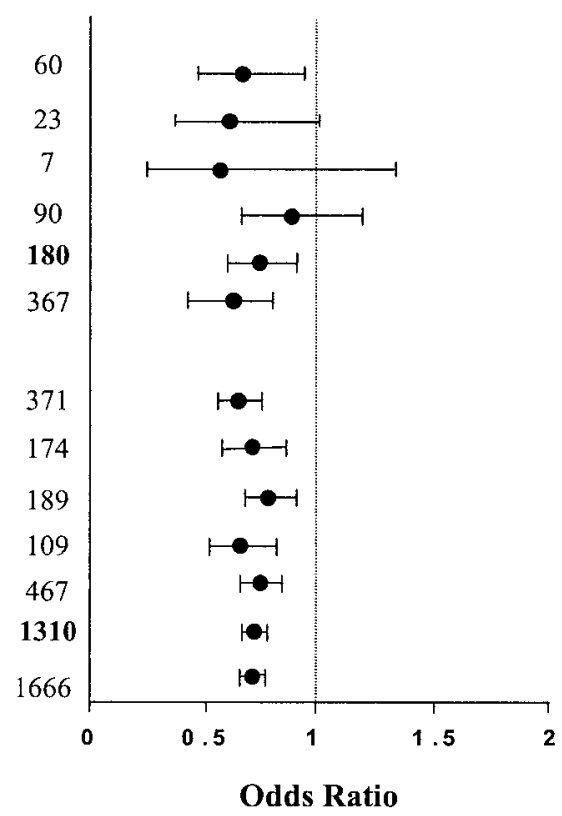

Figure 3. Coronary events (nonfatal myocardial infarction and coronary heart disease death) in women in secondary prevention trials with statins. 4S, Scandinavian Simvastatin Survival Study; CARE, Cholesterol And Recurrent Events; AFCAPS/TexCaps, Air Force/Texas Coronary Atherosclerosis Prevention Study; LIPID, Long-term Intervention with Pravastatin in Ischemic Disease; WOSCOPS, West Of Scotland COronary Prevention Study; HPS, Heart Protection Study. HPS data are for major vascular events including nonfatal myocardial infarction, coronary heart disease death, revascularization, and stroke. [Adapted from LaRosa JC, He J, Vupputuri S. Effect of statins on risk of coronary disease: a meta-analysis of randomized controlled trials. JAMA 1999;282:2340-2346. Copyright (c) 1999 American Medical Association. Used with permission; additional data from ref. 19.

ing Arm, ${ }^{50}$ had contradictory findings, which showed no benefit with statin therapy in women. These trials were of shorter duration, however, accruing a smaller number of events in the women studied.

Statins have proved to be extremely safe and well tolerated in the majority of patients. Their most common serious adverse effects, hepatotoxicity and myopathy, occur at very low rates. ${ }^{51}$ The risk of myopathy increases with advanced age, especially in women, in patients with multisystem disease, and in patients taking specific concomitant medications. ${ }^{51}$ With appropriate care, statins can be used safely in these patients. Statins, however, should not be used in pregnant women, because they have not been tested in this population. Women of childbearing potential who use statins should be counseled about the need for adequate contraception and prenatal planning.
Niacin

Niacin reduces the hepatic synthesis of very lowdensity lipoprotein and triglycerides by inhibiting mobilization of free fatty acids from peripheral adipose tissue to the liver. Because less very lowdensity lipoprotein is available to be used as a substrate, LDL-C levels fall. By blocking hepatic uptake of apolipoprotein A-1, niacin also decreases HDL-C clearance, thereby increasing the amount of HDL available for reverse cholesterol transport. Among available lipid-modifying drugs, niacin has the greatest effect on HDL-C; it also effectively decreases triglycerides, LDL-C, and lipoprotein(a). ${ }^{15}$ Niacin has also been shown to increase LDL particle size, which may make it a particularly good choice when the atherogenic lipid triad is present. ${ }^{52}$ The new AHA guidelines for women recommend niacin for the treatment of low 


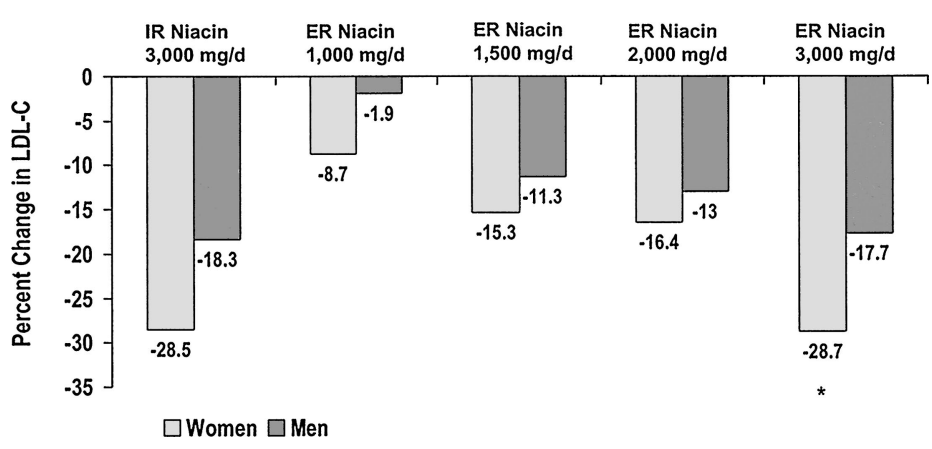

Figure 4. Sex differences in LDL-C with IR and ER niacin. *, $P=.006$. ER, extended-release; IR, immediaterelease. Data are from ref. 57.

HDL-C and elevated triglyceride levels, once the LDL-C goal has been achieved. ${ }^{28}$

In one of the earliest lipid-lowering trials, the Coronary Drug Project, ${ }^{53}$ niacin significantly reduced the risk of recurrent myocardial infarction in men; a subsequent 15 -year follow-up study revealed that, 9 years after study termination, total mortality was decreased in patients who had originally received niacin. ${ }^{54}$ No long-term clinical trials studying the effects of niacin monotherapy on clinical outcomes in women. The Stockholm Ischemic Heart Study ${ }^{55}$ and HDL-Atherosclerosis Treatment Study, ${ }^{56}$ which studied combination therapy with niacin/clofibrate and niacin/simvastatin therapy, respectively, did include women. Women comprised $13 \%$ of the subjects in the HDLAtherosclerosis Treatment Study. This study revealed a $60 \%$ to $90 \%$ reduction in the risk of coronary events and a decrease in angiographic progression: the average stenosis regressed $0.4 \%$ in patients treated with niacin/simvastatin versus a $3.9 \%$ progression with placebo. ${ }^{56}$ The mean reductions in LDL-C and triglycerides were $42 \%$ and $36 \%$, respectively; HDL-C levels increased by $26 \%$.

Women tend to achieve greater LDL-C reductions with niacin than do men. ${ }^{57,58}$ In a doseescalation study of extended-release (ER) niacin, reductions in LDL-C from baseline were significantly greater in women than in men at a dosage of $3000 \mathrm{mg} /$ day $(-28.7 \%$ vs $-17.7 \%)$, and nonsignificant trends favoring women occurred at dosages of 1000 and $2000 \mathrm{mg} /$ day (Figure 4). ${ }^{57} \mathrm{In}$ a pooled analysis of 5 controlled studies of ER niacin, reductions in LDL-C were significantly greater in women than in men with dosages of 1000 and 2000 $\mathrm{mg} /$ day and a nonsignificant trend favoring women was seen for lowering of triglycerides. ${ }^{59}$ It is pos- sible, therefore, that given the relative prognostic significance of HDL-C and triglycerides in women, added to the sex-based difference in lowering of LDL-C, niacin may be especially important in women because of its effects on HDL-C and lipoprotein(a). The more substantial LDL-C response to niacin in women may allow use of lower doses.

Although niacin has a beneficial effect on the overall lipid profile, its use has been limited by side effects, such as prostaglandin-mediated facial and truncal flushing. This effect occurs equally in men and women. Both the incidence and the severity of this side effect can be reduced by starting with a low dose of niacin and slowly titrating up and by avoiding compounds that are known to increase flushing, such as caffeine-containing beverages and alcohol. Flushing can also be dramatically reduced by taking aspirin or ibuprofen 30 to 60 minutes before taking the first niacin dose. ${ }^{60}$ With continued therapy, the incidence and severity of flushing frequently attenuates. Niacin is currently available in 3 formulations: immediate-release (IR), sustained-release (SR), and ER. In response to the high rate of flushing associated with IR niacin, SR niacin was developed to reduce the incidence and severity of flushing. Some SR formulations have been associated with significant hepatotoxicity. ${ }^{61}$ The differences in side-effect profiles (flushing and hepatotoxicity) among the different niacin formulations is directly related to differences in the pharmacokinetic profiles. The incidence of flushing is directly proportional to the rate of absorption. The risk of hepatotoxicity seems to be indirectly related to the rate of absorption although a head-to-head comparison of the 3 formulations addressing the rela- 
tive incidence of hepatotoxicity has not been performed.

The HDL-C raising effect of some SR formulations is less than IR niacin. ${ }^{61}$ The newest formulation, ER niacin, is available by prescription only and has an absorption rate between those of IR and SR niacin..$^{62,63}$ In a comparison study, ER niacin had a safety and efficacy profile, except for fewer flushing episodes, similar to that of IR niacin. ${ }^{62}$

In addition, niacin can cause gastrointestinal symptoms, hyperuricemia, gout, and hyperglycemia. These latter reactions, in addition to hepatotoxicity, seem to be dose-related and are more prevalent at doses $\geq 2$ g. ${ }^{15}$ Finally, niacin has been associated, although rarely, with statin-induced myopathy. ${ }^{51}$ Whether niacin actually increases this risk is unknown; in one phase IV postmarketing surveillance study, only 4 of the 871 reports of statin-induced rhabdomyolysis to the Food and Drug Administration involved concomitant niacin. ${ }^{64}$

\section{Fibrates}

The exact mechanism of action of fibrates is not completely understood. Fibrates are peroxisome proliferator-activated receptor- $\alpha$ agonists, a nuclear transcription factor involved in lipid metabolism and activated by fatty acids. ${ }^{15,65}$ Through an increase in lipoprotein lipase activity and downregulation of apolipoprotein C-III, they may increase the catabolism of triglyceride-rich lipoproteins. Fibrates increase fatty acid oxidation, reducing the formation of very low-density lipoprotein triglycerides, thereby reducing serum triglyceride levels. Fibrates raise HDL-C by increasing the synthesis of apolipoprotein A-I and A-II and reducing HDL catabolism. Fibrates are primarily effective in lowering triglyceride levels but also have moderate HDL-C-raising effects and modest LDL-C-lowering effects, and they increase LDL particle size. ${ }^{15}$ They are another good option for patients with atherogenic dyslipidemia. The new AHA guidelines for women recommend fibrates for the treatment of elevated triglyceride and low HDL-C levels, once the LDL-C goal has been achieved. $^{28}$

Reductions in cardiovascular events associated with fibrate therapy have been documented mainly in men. In the Helsinki Heart Study, gemfibrozil reduced the incidence of CHD events by $34 \%(P<$ $.02)$ in 4081 men with no symptoms of CHD. ${ }^{66}$ In the Veterans Affairs High-density lipoprotein Intervention Trial, gemfibrozil reduced the risk of coronary death or nonfatal myocardial infarction by $22 \%(P=.006)$ in men with CHD, low HDL-C, and mildly elevated LDL-C. ${ }^{67}$ This study provided the first direct clinical evidence that raising HDL-C, in the absence of any change in LDL-C, is associated with cardiovascular risk reduction. ${ }^{68}$ It is interesting that this intervention study upheld the observation noted in the Framingham Heart Study that for every $1 \mathrm{mg} / \mathrm{dL}$ rise in HDL-C level, there was a $3 \%$ reduction in cardiovascular risk. The earlier Coronary Drug Project study with clofibrate, however, failed to demonstrate any short- or long-term risk reduction, an outcome probably attributable to the study drug. ${ }^{53,54}$

The limited outcome data pertaining to women have generally shown benefit from treatment with fibrates. In the Bezafibrate Infarction Prevention study, in which $9 \%$ of the study population was female $(\mathrm{n}=265)$, the risk of myocardial infarction or sudden death was reduced by $9.4 \%(P=.26) .{ }^{69}$ In the Stockholm Ischemic Heart Disease Secondary Prevention Study, which included 113 women with a history of myocardial infarction, the combination of clofibrate and niacin reduced total mortality in the study population overall by $26 \%(P<$ $.05) .{ }^{55}$ Women were not analyzed separately in either study. However, men and women showed equivalent benefits in the Diabetes Atherosclerosis Intervention Study, which included 113 women with diabetes and CHD. ${ }^{70}$ Treatment with fenofibrate reduced angiographic progression compared with placebo. Although the study was not powered for clinical outcomes, the fenofibrate group also experienced fewer cardiac events (38 vs 50 ).

Fibrates are generally well tolerated. Gastrointestinal complaints are the most common side effects; they may also increase the risk of cholesterol gallstones because they enhance the lithogenicity of bile. In addition, fibrates are strongly proteinbound and may interact with other protein-binding drugs, such as warfarin. The main concern is an increased risk of myopathy when fibrates are used in combination with statins, particularly in patients with renal impairment. In 871 reports of statinassociated rhabdomyolysis, concomitant use of fibrates was listed in 80 cases $(9.2 \%) .{ }^{64}$ However, this combination can be used safely with appropriate monitoring. ${ }^{15,51}$ Fenofibrate may carry a lower 
safety risk than gemfibrozil in combination therapy with a statin. ${ }^{71}$

\section{Bile Acid Sequestrants/Cholesterol Absorption Inbibitors}

Bile acid sequestrants are anion-exchange resins that bind bile acids in the ileum, preventing their reabsorption and reducing their enterohepatic recirculation. By decreasing circulating levels of bile acids, through feedback regulation, there is an increase in the conversion of cholesterol into bile acids. The resulting decrease in cholesterol leads to an up-regulation of LDL receptors and lower serum LDL-C levels. Bile acid sequestrants lower plasma levels of LDL-C and produce minimal effects on HDL-C and triglycerides. However, because they can potentially raise triglycerides, their use is contraindicated in persons with significant elevations in triglyceride levels $(>400 \mathrm{mg} / \mathrm{dL})$ or familial dysbetalipoproteinemia. ${ }^{15,72}$ Bile acid sequestrants have been shown to reduce cardiovascular events, total mortality, and atherosclerotic progression in clinical trials involving men. ${ }^{73,74}$

In addition to binding cholesterol, bile acid sequestrants can also reduce the absorption of numerous drugs through the same mechanism. Thus, concomitant medications should be administered at least 1 hour before or 4 hours after dosing. In this class, colesevelam is the least likely to bind with other drugs in the gut. ${ }^{75}$ Bile acid sequestrants are limited by gastrointestinal side effects; however, because they lack systemic effects and because they are a useful therapeutic option in women of childbearing potential and in patients who have demonstrated hepatotoxicity in response to statin therapy and have been unable to tolerate niacin. ${ }^{15,76}$

Cholesterol absorption inhibitors inhibit the intestinal absorption of cholesterol. The reduction in delivery of intestinal cholesterol to the liver results in a reduction of hepatic cholesterol stores and, therefore, an increase in the hepatic uptake of cholesterol from the blood leading to lower serum levels. Ezetimibe, the first available selective cholesterol absorption inhibitor, is thought to involve selective inhibition of the putative sterol transported on the brush-border surface of intestinal epithelial cells. Ezetimibe has been shown in clinical studies of men and women to significantly reduce LDL-C but has minimal effects on HDL-C and triglycerides. ${ }^{72,77}$ Safety data have been principally derived from short-term clinical studies, in which adverse effects and discontinuation rates were similar to those with placebo. ${ }^{72,77}$ Ezetimibe has not been adequately evaluated in either pregnant or nursing women.

\section{Combination Therapy}

The shift to using combination therapy in diseases such as hypertension and diabetes is now also being seen in the treatment of dyslipidemia. This is occurring as a result of suboptimal effects of monotherapy in many patient groups, such as those with heterozygous hypercholesterolemia and familial combined hyperlipidemia. Although the ideal initial therapeutic approach is a statin in most patient groups, frequently this approach alone does not achieve target goals for all lipid parameters. Once combination therapy is being considered, the concept of patient adherence and compliance becomes an issue. Lack of compliance is common and may be considered a result of 2 main causes: cost and ease of use. As a result, fixed-dose combination products are appearing on the market for the management of hypertension, diabetes, and dyslipidemia at increasing frequency and are gaining popularity among physicians and patients alike. Many patients managed in practice have multiple comorbidities, such as coexistent hypertension and dyslipidemia. Fixed-dose combination therapy probably has an even greater appeal in this setting.

\section{Statin/Niacin}

The combination of a statin plus niacin is perhaps one of the most useful combinations for treating dyslipidemia in women, because it adds the favorable effects of niacin on atherogenic dyslipidemia to the powerful LDL-C-lowering action of statins. In clinical studies, this combination has shown improvements across the lipid profile. ${ }^{56,58,78}$ The greater LDL-C-lowering effects of niacin monotherapy seem to continue when niacin is given in combination. In a small study of fluvastatin and niacin, LDL-C levels were reduced by $54.6 \%$ in women versus $38.2 \%$ in men $(P<.0005)$ (Figure 5). ${ }^{58}$ Combination therapy with niacin, colestipol, and/or lovastatin also resulted in a better reduction in coronary artery stenosis in women than men among persons with familial hypercholesterolemia. ${ }^{79}$ Studies such as the HDL-Atherosclerosis Treatment Study and University of California, San Francisco, Arteriosclerosis Specialized Center of 


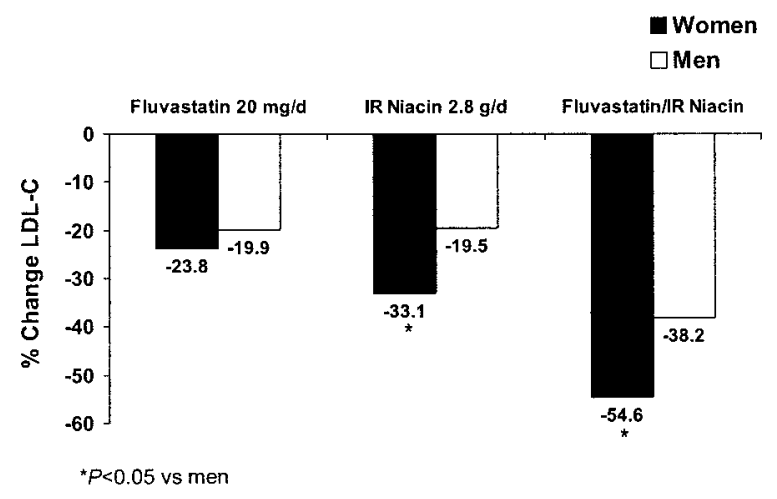

Figure 5. Sex differences in LDL-C response with statin/niacin combination therapy and monotherapy. *, $P<.05$. LDL-C, low-density lipoprotein cholesterol. Data are from ref. 58.

Research trials have demonstrated the benefit of combination therapy with an LDL-C-lowering drug and niacin on clinical outcomes as well as on regression of atherosclerotic lesions. ${ }^{56,79}$ Considering that most of the patients in University of California, San Francisco, Arteriosclerosis Specialized Center of Research (92\%) were asymptomatic, the findings suggest that combination lipid-modifying therapy can be beneficial to patients with subclinical atherosclerosis who are at high risk. ${ }^{79}$

A fixed-dose combination product, ER niacin/ lovastatin is available as a once-at-bedtime formulation. The long-term safety and effectiveness of this formulation has been studied in 814 patients with dyslipidemia, including 296 women. At escalating doses of ER niacin/lovastatin, from 500/10 $\mathrm{mg}$ to $2000 / 40 \mathrm{mg}$, dose-dependent effects were observed for all major lipid parameters. By week 16 , LDL-C was lowered by $47 \%$, triglycerides by $41 \%$, and HDL-C was increased $30 \%$. In addition, HDL-C levels continued to increase between weeks 16 and 52, culminating in an increase of $41 \%$ at 1 year. ${ }^{80}$ Compared with statin monotherapy, ER niacin/lovastatin showed LDL-C-lowering efficacy comparable with $10 \mathrm{mg}$ of atorvastatin and greater than $20 \mathrm{mg}$ of simvastatin and was significantly more effective than either atorvastatin or simvastatin in raising HDL-C. ${ }^{81}$

The combination of a statin with niacin is generally well tolerated. In the long-term study described above, $10 \%$ of patients withdrew because of flushing, and there were no cases of drug-induced myopathy. ${ }^{80}$
Statin/Fibrate

Combining statin therapy with a fibrate is another good option for patients with mixed dyslipidemia. ${ }^{82-84}$ Although no outcome studies have been performed with this combination, one study showed a reduction in projected coronary risk. ${ }^{83}$ As mentioned, myopathy is a potential concern when using this combination, but the risks can be attenuated by avoiding use in patients with renal impairment and appropriately monitoring patients and using moderate doses. ${ }^{51,85}$

\section{Statin/Bile Acid Sequestrant or Statin/Cholesterol Absorption Inbibitors}

Adding a bile acid sequestrant or ezetimibe to statin therapy may be a good option for patients who need additional LDL-C-lowering but do not have abnormalities of other lipoproteins. The combination of pravastatin plus cholestyramine was found in one study to be more effective than monotherapy with either agent alone in lowering LDL-C in both men and women. ${ }^{86}$ Ezetimibe added to ongoing statin therapy resulted in significant reductions in LDL-C of $25 \%$ and triglycerides of $14 \%$ and increases in HDL-C of $2.7 \%$; all changes were significantly greater than those seen with statin monotherapy. ${ }^{87}$

\section{Niacin/BAS}

Niacin plus a bile acid sequestrant may be suitable for patients who are refractory to or intolerant of statins. This combination has been shown to favorably alter the lipid profile, reduce cardiovascular events, and promote regression of atherosclerotic plaque; these data are from an all-male population. $^{74,88,89}$

\section{Multiple Combination Therapy}

An evaluation of intensive lipid-modifying therapy with lovastatin, niacin, and colestipol in patients enrolled in the Familial Atherosclerosis Treatment Study showed that this triple therapy was associated with a significant reduction in LDL-C $(-48 \%)$ and triglyceride levels $(-36 \%)$, an increase in HDL-C $(+23 \%)$, and a significantly lower rate of death and cardiovascular events $(P<.05) .{ }^{90}$ Adding a third lipid-modifying agent may be considered in patients who require extremely aggressive risk reduction and those with lipid abnormalities despite current combination therapy. 


\section{Conclusions}

Cardiovascular disease is a serious epidemic in the female population. It is imperative for clinicians to increase their awareness of sex-based differences in risk factors, lipid profiles, and treatment response to effectively refocus cardiovascular care in this population. Current research suggests that wellproven treatment options are underused in women, including lipid-modifying therapies. Cardiovascular risk factors should be assessed in women starting much earlier than menopause and should be treated as aggressively in women as in men. In light of evidence suggesting that HDL-C and triglyceride levels may be more important predictors of cardiovascular risk than total cholesterol or LDL-C, optimal treatment of women with dyslipidemia should start with LDL-C but not end there; triglycerides, HDL-C and, when appropriate, other markers of risk should be measured and abnormalities addressed. Combination therapy is an important therapeutic option that should be considered for all patients, including female patients in need of aggressive improvements in multiple lipid parameters.

\section{References}

1. American Heart Association. Heart disease and stroke statistics-2003 update [monograph on the Internet]. Dallas (TX): American Heart Association; 2003 [cited 2003 Dec 8]. Available from: http://www.americanheart.org/downloadable/heart/ 1040391091015HDS_Stats_03.pdf.

2. Mosca L, Jones WK, King KB, Ouyang P, Redberg RF, Hill MN, for the American Heart Association Women's Heart Disease and Stroke Campaign Task Force. Awareness, perception, and knowledge of heart disease risk and prevention among women in the United States. Arch Fam Med 2000;9:506-15.

3. Rossouw JE, Anderson GL, Prentice RL, et al., for the Writing Group for the Women's Health Initiative Investigators. Risks and benefits of estrogen plus progestin in healthy postmenopausal women: principal results from the Women's Health Initiative randomized controlled trial. JAMA 2002;288: 321-33.

4. Hulley S, Grady D, Bush T, et al., for the Heart and Estrogen/progestin Replacement Study (HERS) Research Group. Randomized trial of estrogen plus progestin for secondary prevention of coronary heart disease in postmenopausal women. JAMA 1998;280: 605-13.

5. Lewis SJ, Sacks FM, Mitchell JS, et al., for The CARE Investigators. Effect of pravastatin on cardiovascular events in women after myocardial infarc- tion: the cholesterol and recurrent events (CARE) trial. J Am Coll Cardiol 1998;32:140-6.

6. Basaria S, Dobs AS. Treatment of hyperlipidemia in women. Int J Fertil Womens Med 2000;45:22-33.

7. Kudenchuk PJ, Maynard C, Martin JS, Wirkus M, Weaver WD. Comparison of presentation, treatment, and outcome of acute myocardial infarction in men versus women (the Myocardial Infarction Triage and Intervention Registry). Am J Cardiol 1996; 78:9-14.

8. Goldberg RJ, O’Donnell C, Yarzebski J, Bigelow C, Savageau J, Gore JM. Sex differences in symptom presentation associated with acute myocardial infarction: a population-based perspective. Am Heart J 1998;136:189-95.

9. Alexander KP, Peterson ED. Medical and surgical management of coronary artery disease in women. Am J Manag Care 2001;7:951-6.

10. Kyker KA, Limacher MC. Gender differences in the presentation and symptoms of coronary artery disease. Curr Womens Health Rep 2002;2:115-9.

11. DeVon HA, Zerwic JJ. The symptoms of unstable angina: do women and men differ? Nurs Res 2003; 52:108-18.

12. Miller M, Byington R, Hunninghake D, Pitt B, Furberg CD, for the Prospective Randomized Evaluation of the Vascular Effects of Norvasc Trial (PREVENT) Investigators. Sex bias and underutilization of lipid-lowering therapy in patients with coronary artery disease at academic medical centers in the United States and Canada. Arch Intern Med 2000;160:343-7.

13. Shaw LJ, Miller DD, Romeis JC, Kargl D, Younis LT, Chaitman BR. Gender differences in the noninvasive evaluation and management of patients with suspected coronary artery disease. Ann Intern Med 1994;120:559-66.

14. Schrott HG, Bittner V, Vittinghoff E, Herrington DM, Hulley S, for the HERS Research Group. Adherence to National Cholesterol Education Program Treatment goals in postmenopausal women with heart disease: the Heart and Estrogen/Progestin Replacement Study (HERS). JAMA 1997;277:1281-6.

15. Expert Panel on Detection, Evaluation, and Treatment of High Blood Cholesterol in Adults (Adult Treatment Panel III). Third Report of the National Cholesterol Education Program (NCEP) Expert Panel on Detection, Evaluation, and Treatment of High Blood Cholesterol in Adults (Adult Treatment Panel III) final report. Circulation 2002;106:31433421.

16. Clearfield M, Downs JR, Weis S, et al. Air Force/ Texas Coronary Atherosclerosis Prevention Study (AFCAPS/TexCAPS): efficacy and tolerability of long-term treatment with lovastatin in women. J Womens Health Gend Based Med 2001;10:971-81.

17. Miettinen TA, Pyörälä K, Olsson AG, et al., for the Scandinavian Simvastatin Study Group. Cholesterol- 
lowering therapy in women and elderly patients with myocardial infarction or angina pectoris: findings from the Scandinavian Simvastatin Survival Study (4S). Circulation 1997;96:4211-8.

18. Long-Term Intervention with Pravastatin in Ischaemic Disease (LIPID) Study Group. Prevention of cardiovascular events and death with pravastatin in patients with coronary heart disease and a broad range of initial cholesterol levels. $\mathrm{N}$ Engl J Med 1998;339:1349-57.

19. Heart Protection Study Collaborative Group. MRC/ BHF Heart Protection Study of cholesterol lowering with simvastatin in 20536 high-risk individuals: a randomised placebo-controlled trial. Lancet 2002; 360:7-22.

20. Mosca L, Manson JE, Sutherland SE, Langer RD, Manolio T, Barrett-Connor E. Cardiovascular disease in women: a statement for healthcare professionals from the American Heart Association. Circulation 1997;96:2468-82.

21. Grady D, Rubin SM, Petitti DB, et al. Hormone therapy to prevent disease and prolong life in postmenopausal women. Ann Intern Med 1992;117: 1016-37.

22. Stampfer MJ, Colditz GA. Estrogen replacement therapy and coronary heart disease: a quantitative assessment of the epidemiologic evidence. Prev Med 1991;20:47-63.

23. Lee RT, Libby P. The unstable atheroma. Arterioscler Thromb Vasc Biol 1997;17:1859-67.

24. Writing Group for the PEPI Trial T. Effects of estrogen or estrogen/progestin regimens on heart disease risk factors in postmenopausal women. The Postmenopausal Estrogen/Progestin Interventions (PEPI) Trial. JAMA 1995;273:199-208.

25. Anderson GL, Limacher M, Assaf AR, et al. Effects of conjugated equine estrogen in postmenopausal women with hysterectomy: the Women's Health Initiative randomized controlled trial. JAMA 2004; 291:1701-12.

26. Waters DD, Alderman EL, Hsia J, et al. Effects of hormone replacement therapy and antioxidant vitamin supplements on coronary atherosclerosis in postmenopausal women: a randomized controlled trial. JAMA 2002;288:2432-40.

27. Pearson TA, Blair SN, Daniels SR, et al. AHA Guidelines for Primary Prevention of Cardiovascular Disease and Stroke: 2002 Update: Consensus Panel Guide to Comprehensive Risk Reduction for Adult Patients Without Coronary or Other Atherosclerotic Vascular Diseases. Circulation 2002;106: 388-91.

28. Mosca L, Appel LJ, Benjamin EJ, et al. Evidencebased guidelines for cardiovascular disease prevention in women. Circulation 2004;109:672-93.

29. Downs JR, Clearfield M, Weis S, et al., for the Air Force/Texas Coronary Atherosclerosis Prevention Study. Primary prevention of acute coronary events with lovastatin in men and women with average cholesterol levels: results of AFCAPS/TexCAPS. JAMA 1998;279:1615-22.

30. Scandinavian Simvastatin Survival Study Group. Randomised trial of cholesterol lowering in 4444 patients with coronary heart disease: the Scandinavian Simvastatin Survival Study (4S). Lancet 1994; 344:1383-9.

31. Shepherd J, Cobbe SM, Ford I, et al., for the West of Scotland Coronary Prevention Study Group. Prevention of coronary heart disease with pravastatin in men with hypercholesterolemia. N Engl J Med 1995; 333:1301-7.

32. Wenger NK. Hypertension and other cardiovascular risk factors in women. Am J Hypertens 1995;8: 94s-9s.

33. Blake GJ, Otvos JD, Rifai N, Ridker PM. Lowdensity lipoprotein particle concentration and size as determined by nuclear magnetic resonance spectroscopy as predictors of cardiovascular disease in women. Circulation 2002;106:1930-7.

34. Carr MC, Kim KH, Zambon A, et al. Changes in LDL density across the menopausal transition. J Investig Med 2000;48:245-50.

35. Castelli WP, Garrison RJ, Wilson PWF, Abbott RD, Kalousdian S, Kannel WB. Incidence of coronary heart disease and lipoprotein cholesterol levels. The Framingham Study. JAMA 1986;256:2835-8.

36. Castelli WP. Epidemiology of triglycerides: a view from Framingham. Am J Cardiol 1992;70:3H-9H.

37. Castelli WP, Anderson K, Wilson PWF, Levy D. Lipids and risk of coronary heart disease: the Framingham Study. Ann Epidemiol 1992;2:23-8.

38. Bass KM, Newschaffer CJ, Klag MJ, Bush TL. Plasma lipoprotein levels as predictors of cardiovascular death in women. Arch Intern Med 1993;153: 2209-16.

39. Hokanson JE, Austin MA. Plasma triglyceride level is a risk factor for cardiovascular disease independent of high-density lipoprotein cholesterol level: a metaanalysis of population-based prospective studies. J Cardiovasc Risk 1996;3:213-9.

40. Shlipak MG, Simon JA, Vittinghoff E, et al. Estrogen and progestin, lipoprotein(a), and the risk of recurrent coronary heart disease events after menopause. JAMA 2000;283:1845-52.

41. Kannel WB, McGee DL. Diabetes and glucose tolerance as risk factors for cardiovascular disease: the Framingham study. Diabetes Care 1979;2:120-6.

42. Manson JE, Colditz GA, Stampfer MJ, et al. A prospective study of maturity-onset diabetes mellitus and risk of coronary heart disease and stroke in women. Arch Intern Med 1991;151:1141-7.

43. Haffner SM. Metabolic syndrome, diabetes and coronary heart disease. Int J Clin Pract 2002;(suppl 132):31-7.

44. Bermudez EA, Rifai N, Buring J, Manson JE, Ridker PM. Interrelationships among circulating interleu- 
kin-6, C-reactive protein, and traditional cardiovascular risk factors in women. Arterioscler Thromb Vasc Biol 2002;22:1668-73.

45. Ridker PM, Hennekens CH, Buring JE, Rifai N. C-reactive protein and other markers of inflammation in the prediction of cardiovascular disease in women. N Engl J Med 2000;342:836-43.

46. Mosca L. C-reactive protein-to screen or not to screen? N Engl J Med 2002;347:1615-7.

47. Pearson TA, Mensah GA, Alexander RW, et al. Markers of inflammation and cardiovascular disease: application to clinical and public health practice: a statement for healthcare professionals from the Centers for Disease Control and Prevention and the American Heart Association. Circulation 2003;107: 499-511.

48. LaRosa JC, He J, Vupputuri S. Effect of statins on risk of coronary disease: a meta-analysis of randomized controlled trials. JAMA 1999;282:2340-6.

49. Shepherd J, Blauw GJ, Murphy MB, et al., on behalf of the PROSPER study group. Pravastatin in elderly individuals at risk of vascular disease (PROSPER): a randomised controlled trial. Lancet 2002;360: 1623-30.

50. Sever PS, Dahlöf B, Poulter NR, et al., for the ASCOT investigators. Prevention of coronary and stroke events with atorvastatin in hypertensive patients who have average or lower-than-average cholesterol concentrations, in the Anglo-Scandinavian Cardiac Outcomes Trial-Lipid Lowering Arm (ASCOT-LLA): a multicentre randomised controlled trial. Lancet 2003;361:1149-58.

51. Pasternak RC, Smith SC Jr, Bairey-Merz CN, Grundy SM, Cleeman JI, Lenfant C. ACC/AHA/ NHLBI clinical advisory on the use and safety of statins. J Am Coll Cardiol 2002;40:567-72.

52. Superko HR, Krauss RM. Differential effects of nicotinic acid in subjects with different LDL subclass patterns. Atherosclerosis 1992;95:69-76.

53. The Coronary Drug Project Research Group. Clofibrate and niacin in coronary heart disease. JAMA 1975;231:360-81.

54. Canner PL, Berge KG, Wenger NK, et al., for the Coronary Drug Project Research Group. Fifteen year mortality in Coronary Drug Project patients: long-term benefit with niacin. J Am Coll Cardiol 1986;8:1245-55.

55. Carlson LA, Rosenhamer G. Reduction of mortality in the Stockholm Ischaemic Heart Disease Secondary Prevention Study by combined treatment with clofibrate and nicotinic acid. Acta Med Scand 1988; 223:405-18.

56. Brown BG, Zhao XQ, Chait A, et al. Simvastatin and niacin, antioxidant vitamins, or the combination for the prevention of coronary disease. N Engl J Med 2001;345:1583-92.

57. Goldberg AC. Clinical trial experience with ex- tended-release niacin (Niaspan): dose-escalation study. Am J Cardiol 1998;82:35U-38U.

58. Jacobson TA, Jokubaitis LA, Amorosa LF. Fluvastatin and niacin in hypercholesterolemia: a preliminary report on gender differences in efficacy. Am J Med 1994;96:64S-68S.

59. Goldberg AC, McGovern ME, Simmons PD. Lack of gender effect in the response of high-density lipoprotein cholesterol or lipoprotein (A) to extendedrelease niacin [oral presentation]. International Symposium on Triglycerides, Metabolic Disorders, and Cardiovascular Disease; 2003 Jul 10-13; New York, New York.

60. Whelan AM, Price SO, Fowler SF, Hainer BL. The effect of aspirin on niacin-induced cutaneous reactions. J Fam Pract 1992;34:165-8.

61. McKenney JM, Proctor JD, Harris S, Chinchili VM. A comparison of the efficacy and toxic effects of sustained- vs immediate-release niacin in hypercholesterolemic patients. JAMA 1994;271:672-7.

62. Knopp RH, Alagona P, Davidson M, et al. Equivalent efficacy of a time-release form of niacin (Niaspan) given once-a-night versus plain niacin in the management of hyperlipidemia. Metabolism 1998; 47:1097-1104.

63. Pieper JA. Understanding niacin formulations. Am J Manag Care 2002;8(12 suppl):S308-S314.

64. Omar MA, Wilson JP. FDA adverse event reports on statin-associated rhabdomyolysis. Ann Pharmacother 2002;36:288-95.

65. Fruchart JC, Duriez P, Staels B. Peroxisome proliferator-activated receptor-alpha activators regulate genes governing lipoprotein metabolism, vascular inflammation and atherosclerosis. Curr Opin Lipidol 1999;10:245-57.

66. Frick MH, Elo O, Haapa K, et al. Helsinki Heart Study: primary-prevention trial with gemfibrozil in middle-aged men with dyslipidemia. Safety of treatment, changes in risk factors, and incidence of coronary heart disease. N Engl J Med 1987;317: $1237-45$.

67. Rubins HB, Robins SJ, Collins D, et al., for the Veterans Affairs High-Density Lipoprotein Cholesterol Intervention Trial Study Group. Gemfibrozil for the secondary prevention of coronary heart disease in men with low levels of high-density lipoprotein cholesterol. N Engl J Med 1999;341:410-8.

68. Robins SJ, Collins D, Wittes JT, et al., for the VA-HIT study group. Relation of gemfibrozil treatment and lipid levels with major coronary events. VA-HIT: a randomized controlled trial. JAMA 2001; 285:1585-91.

69. BIP Study Group. Secondary prevention by raising HDL cholesterol and reducing triglycerides in patients with coronary artery disease: the Bezafibrate Infarction Prevention (BIP) study. Circulation 2000; 102:21-7.

70. Diabetes Atherosclerosis Intervention Study Investi- 
gators. Effect of fenofibrate on progression of coronary-artery disease in type 2 diabetes: the Diabetes Atherosclerosis Intervention Study, a randomised study. Lancet 2001;357:905-10.

71. Davidson MH. Combination therapy for dyslipidemia: safety and regulatory considerations. Am J Cardiol 2002;90(Suppl):50K-60K.

72. Bays HE, Moore PB, Drehobl MA, et al., for the Ezetimibe Study Group. Effectiveness and tolerability of ezetimibe in patients with primary hypercholesterolemia: pooled analysis of two phase II studies. Clin Ther 2001;23:1209-30.

73. Lipid Research Clinics Program. The Lipid Research Clinics Coronary Primary Prevention Trial results. II. The relationship of reduction in incidence of coronary heart disease to cholesterol lowering. JAMA 1984;251:365-74.

74. Blankenhorn DH, Nessim SA, Johnson RL, Sanmarco ME, Azen SP, Cashin-Hemphill L. Beneficial effects of combined colestipol-niacin therapy on coronary atherosclerosis and coronary venous bypass grafts. JAMA 1987;257:3233-40.

75. Donovan JM, Stypinski D, Stiles MR, Olson TA, Burke SK. Drug interactions with colesevelam hydrochloride, a novel, potent lipid-lowering agent. Cardiovasc Drugs Ther 2000;14:681-90.

76. Mosca LJ. Optimal management of cholesterol levels and the prevention of coronary heart disease in women. Am Fam Physician 2002;65:217-26.

77. Dujovne CA, Ettinger MP, McNeer JF, et al., for the Exetimibe Study Group. Efficacy and safety of a potent new selective cholesterol absorption inhibitor. ezetimibe, in patients with primary hypercholesterolemia. Am J Cardiol 2002;90:1092-7.

78. Davignon J, Roederer G, Montigny M, et al. Comparative efficacy and safety of pravastatin, nicotinic acid and the two combined in patients with hypercholesterolemia. Am J Cardiol 1994;73:339-45.

79. Kane JP, Malloy MJ, Ports TA, Phillips NR, Diehl JC, Havel RJ. Regression of coronary atherosclerosis during treatment of familial hypercholesterolemia with combined drug regimens. JAMA 1990;264: 3007-12.

80. Kashyap ML, McGovern ME, Berra K, et al. Longterm safety and efficacy of a once-daily niacin/lova- statin formulation in patients with dyslipidemia. Am J Cardiol 2002;89:672-8.

81. Bays HE, Dujovne CA, McGovern ME, et al. Comparison of once-daily niacin extended-release/ lovastatin with standard doses of atorvastatin and simvastatin (the Advicor Versus Other CholesterolModulating Agents Trial Evaluation [ADVOCATE]). Am J Cardiol 2003;91:667-72.

82. Murdock DK, Murdock AK, Murdock RW, et al. Long-term safety and efficacy of combination gemfibrozil and HMG-CoA reductase inhibitors for the treatment of mixed lipid disorders. Am Heart J 1999; 138:151-5.

83. Athyros VG, Papageorgiou AA, Hatzikonstandinou $\mathrm{HA}$, et al. Safety and efficacy of long-term statinfibrate combinations in patients with refractory familial combined hyperlipidemia. Am J Cardiol 1997; 80:608-13.

84. Iliadis EA, Rosenson RS. Long-term safety of pravastatin-gemfibrozil therapy in mixed hyperlipidemia. Clin Cardiol 1999;22:25-8.

85. Shek A, Ferrill MJ. Statin-fibrate combination therapy. Ann Pharmacother 2001;35:908-17.

86. Eriksson M, Hadell K, Holme I, Walldius G, Kjellström T. Compliance with and efficacy of treatment with pravastatin and cholestyramine: a randomized study on lipid-lowering in primary care. J Intern Med 1998;243:373-80.

87. Gagne C, Bays HE, Weiss SR, et al., for the Ezetimibe Study Group. Efficacy and safety of ezetimibe added to ongoing statin therapy for treatment of patients with primary hypercholesterolemia. Am J Cardiol 2002;90:1084-91.

88. Cashin-Hemphill L, Mack WJ, Pogoda JM, Sanmarco ME, Azen SP, Blankenhorn DH. Beneficial effects of colestipol-niacin on coronary atherosclerosis: a 4-year follow-up. JAMA 1990;264:3013-7.

89. Brown G, Albers JJ, Fisher LD, et al. Regression of coronary artery disease as a result of intensive lipidlowering therapy in men with high levels of apolipoprotein B. N Engl J Med 1990;323:1289-98.

90. Brown BG, Brockenbrough A, Zhao XQ, et al. Very intensive lipid therapy with lovastatin, niacin, and colestipol for prevention of death and myocardial infarction: a 10-year familial atherosclerosis treatment study (FATS) follow-up [abstract 3341]. Circulation 1998;98(suppl I):I-635. 